\title{
CORRECTION
}

\section{Correction to: Remarks on Topological Entropy of Random Dynamical Systems}

Zhiming Li $^{1}$ - Zhihui Ding ${ }^{1}$

Published online: 21 November 2017

(C) Springer International Publishing AG, part of Springer Nature 2017

\section{Correction to: Qual. Theory Dyn. Syst. https://doi.org/10.1007/s12346-017-0258-8}

In the original publication of the article, the last name of the second author was incorrect. The correct name of the author should read as "Zhihui Ding".

The original article has been updated accordingly.

The original article can be found online at https://doi.org/10.1007/s12346-017-0258-8.

Zhiming Li

china-lizhiming@163.com

Zhihui Ding

h130701011706@163.com

1 School of Mathematics, Northwest University, Xi'an, People's Republic of China 